\title{
Root Canal Retreatment of Permanent Mandibular Canine with Two Canals - A Case Report
}

\author{
Al Dahman Yousef $\mathrm{H}^{1,2 *}$ and $\mathrm{Al}$ Hawwas Abdullah $\mathrm{Y}^{3}$ \\ ${ }^{1}$ Department of Endodontics, Riyadh Colleges of Dentistry and Pharmacy, Saudi Arabia \\ ${ }^{2}$ Departments of Dental, Ministry of Health, Saudi Arabia \\ ${ }^{3}$ King Saud University Medical City, Saudi Arabia
}

Submission: January 13, 2017; Published: February 23, 2017

*Corresponding author: Yousef Hamad Al-Dahman, Department of Endodontics, Riyadh Colleges of Dentistry and Pharmacy, P. 0. Box: 84891, Riyadh 11681, Kingdom of Saudi Arabia, Saudi Arabia, Email: yousef.aldahman@gmail.com

\begin{abstract}
The knowledge of both the external and internal anatomy of teeth is important for adequate root canal treatment. Permanent mandibular canine usually single-rooted with single root canal. Single-rooted mandibular canine with two canals is rare. This paper describes a case of root canal retreatment of permanent mandibular canine with two root canals and one apical foramen (Type II) in single root. The clinicians must be aware of these anatomical variations and able to use variety of tools for proper diagnosis and management.
\end{abstract}

Keywords: Mandibular canine, Anatomical variation, root canal retreatment

\section{Introduction}

The objectives of root canal treatment are to eliminate infection from root canal and to prevent reinfection. [1]. Failure to locate, clean, shape, or fill all root canals can lead to posttreatment disease, pain, and/or complications of treated tooth [13]. Therefore, a broad knowledge of the root canal anatomy and its variations is mandatory to improve the prognosis of root canal treatment [4].

Generally, mandibular canine is usually single-rooted with single root canal. [5,6] Several reports of anatomical variations of mandibular canine have been reported in the literature. The incidence of a mandibular canine with single-root and two root canals is approximately $15 \%$. [5,7,8] Also, the incidence of mandibular canine having double-roots and two canals was reported to be up to $5 \%[6,9]$. The present case report describes the nonsurgical root canal re treatment of a mandibular canine with single-root and two root canals.

\section{Case Report}

A 38 years old Saudi woman was reported to endodontic postgraduate clinics of Riyadh College's Dental Hospital, Riyadh, Saudi Arabia for nonsurgical endodontic retreatment of mandibular left canine (number \#33). The chief complaint was to complete the root canal retreatment that was started by an undergraduate dental student a week ago. The patient's medical history was noncontributory.
Clinical examinations revealed a temporary restoration on tooth \#33. The tooth was sensitive to percussion and palpation. There was no mobility and the periodontal status was normal. Radiographic examination revealed a previously treated tooth with slight periapical radiolucency related to tooth \#33 (Figure 1). Based on the clinical and radiographic findings and according to American Association of Endodontics consensus, [10] the tooth was diagnosed as previously treated with symptomatic apical periodontitis.

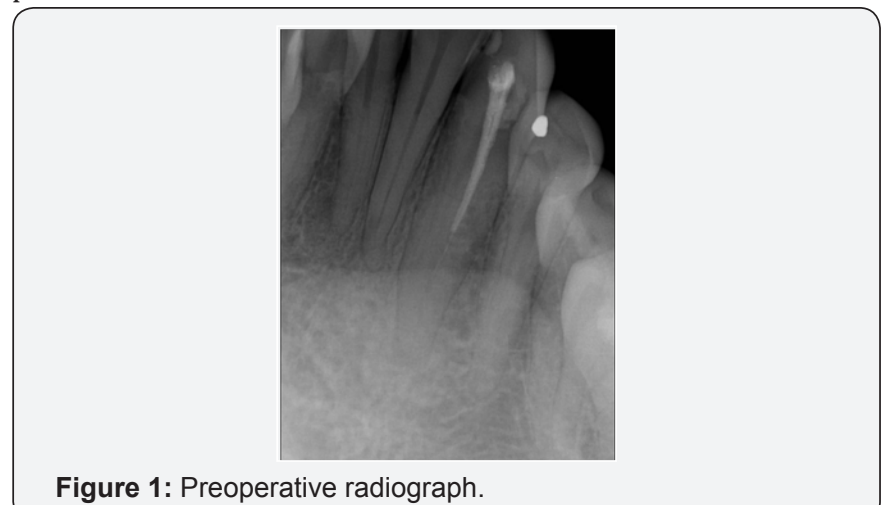

Following the delivery of local anesthesia (2\% lidocaine and 1:100,000 epinephrine) and isolation with rubber dam, removal of the temporary filling was made. The pulpal floor was carefully examined under dental operating microscope (DOM) (Global 
Dental Microscopes, Global Surgical Corporation, USA). Two separate buccal and lingual orifices were identified. The access cavity outline was extended buccolingually to establish straight line access.

The working length was established using electronic apex locator, Root ZX II (J. Morita, Tokyo, Japan), and confirmed radiographically (Figure 2). The buccal canal joined the lingual canal in the middle third of the root (type II Vertucci's classification) [11].

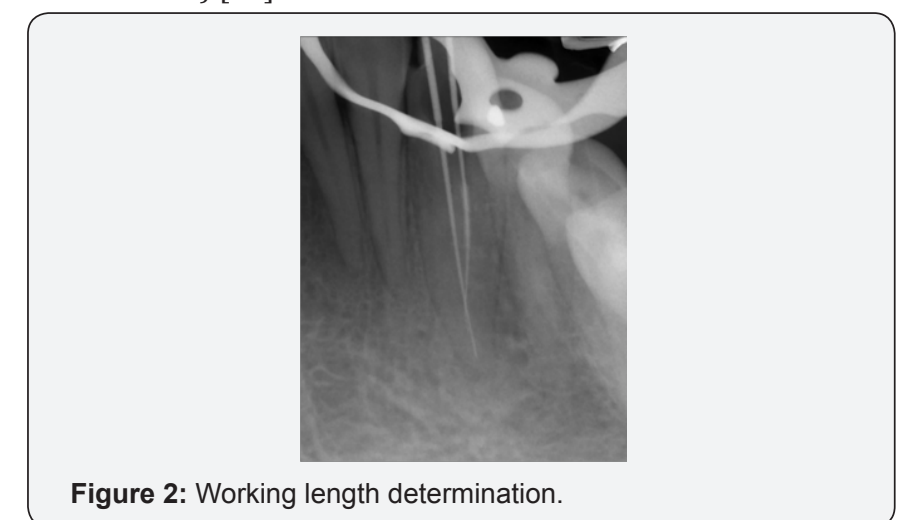

The two canals were shaped by ProTaper Next System (Dentsply Maillefer, Ballaigues, Switzerland) to size X3 for both canals. Copious irrigation with $2.5 \%$ sodium hypochlorite ( $\mathrm{NaOCl}$ ) followed by $17 \%$ ethylenediaminetetraacetic acid (EDTA) was carried out during the instrumentation phase. After the final flush, the canals were dried with paper points and obturated with matching Gutta percha cones and Endosequence BC sealer (Brasseler, Savannah, GA). The access cavity was sealed with Coltosol temporary filling material (Coltosol ${ }^{\circledR}$ F, Coltene, Switzerland), and the patient was referred to receive final restoration (Figure 3).

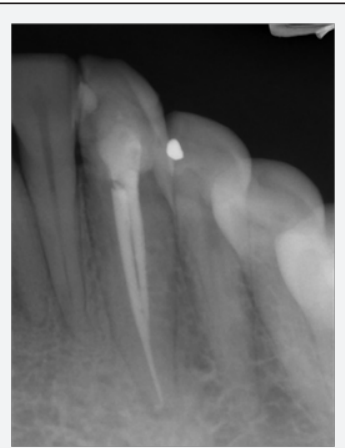

Figure 3: Postoperative radiograph.

\section{Discussion}

Failure to locate, clean, shape, and fill a canal has been demonstrated to be a causative factor in the failure of nonsurgical endodontic therapy $[12,13]$. Teeth with anatomical variation are an important issue in root canal treatment. Missing root canals may contain necrotic tissue and microorganisms. Consequently, this may lead -to development of an apical periodontitis. Thus, clinicians should be aware of complex root canal structure.
Mandibular canines with single-root and single canal are common, however, two root canals, $[5,7,8,14,15]$ and in some unusual cases, there may be one or two roots with three root canals $[16,17]$ has been reported.

In the present case, mandibular canine with single-root and two canals was reported. The incidence of two root canals in single rooted mandibular canine teeth has been reported to be up to $6.25 \%$ [18] with a percentage of $14 \%$ of having Type II canals in mandibular canine [7].

One case report of a Saudi female patient with single-rooted lower canine with two canals was reported [15]. The incidence of two canals in mandibular canine is more in female than male as reported in the literatures [19].

Proper interpretation of conventional periapical radiographs taken in more than one angle is mandatory to detect any morphological variations of teeth [19] Additionally, using advanced diagnostic radiographic techniques such as cone beam computed tomography (CBCT) are very helpful to detect such variations if conventional radiographic techniques lack to provide obvious information and more details are required [20].

Also, using magnification tools, magnification loupes or DOM, might assist in locating and additional canals [21]. In the present case, DOM was used and helped in locating the missed canals [2227].

\section{Conclusion}

Although the occurrence of single-rooted mandibular canine with two canals is infrequent, the clinician should be aware of such anatomical variations in the permanent mandibular canine. Careful interpretation of radiographs along with an appropriate access cavity design and the use of magnifying tools will help in evaluation and detecting such variations. Failure to detect these variations will result in an uninstrumented canals and subsequent failure of the root canal treatment.

\section{References}

1. Sjögren U, Hagglund B, Sundqvist G, Wing K (1990) Factors affecting the long-term results of endodontic treatment. J Endod 16(10): 498504 .

2. Vertucci FJ (2005) Root canal morphology and its relationship to endodontic procedures. Endod Topics 10(1): 3-29.

3. Cantatore G, Berutti E, Castellucci (2009) Missed anatomy: Frequency and clinical impact. Endod Topics 15(1): 3-31.

4. Friedman S (2002) Prognosis of initial endodontic therapy. Endod Topics 2(2): 59-88.

5. Pineda F, Kuttler Y (1972) Mesiodistal and buccolingual roentgenographic investigation of 7,275 root canals. Oral Surg Oral Med Oral Pathol 33(1): 101-110.

6. Ouellet R (1995) Mandibular permanent cuspids with two roots. J Can Dent Assoc 61(2): 159-161.

7. Vertucci FJ (1984) Root canal anatomy of the human permanent teeth. Oral Surg Oral Med Oral Pathol 58(5): 589-599. 
8. Green D (1973) Double canals in single roots. Oral Surg Oral Med Oral Pathol 35(5): 689-696.

9. Pécora JD, Sousa Neto MD, Saquy PC (1993) Internal anatomy, direction and number of roots and size of human mandibular canines. Braz Dent J 4(1): 53-57.

10. Glickman GN (2009) AAE Consensus on Diagnostic Terminology: background and perspectives. J Endod 35(12): 1619-1620.

11. Vertucci FJ (1984) Root canal anatomy of the human permanent teeth. Oral Surg 58(5): 589-599.

12. Seltzers S, Bender IB, Ziontz M (1963) The Interrelationship of pulp and periodontal disease. Oral Surg Oral Med Oral Pathol 16(12): $1474-1490$

13. Hulsmann M, Schafer E (2009) Problems in gaining access to the root canal system. In: Hulsmann Michael, Schafer Edgar (Eds.), Problems in Endodontics: Etiology, Diagnosis and Treatment. (1 $1^{\text {st }}$ edn), Quintessence Publishing Co Ltd., Germany, pp. 145-172.

14. Sert S, Bayirli GS (2004) Evaluation of the root canal configurations of the mandibular and maxillary permanent teeth by gender in the Turkish population. J Endod 30(6): 391-398.

15. Alenezi MA, Al-Hawwas AY (2016) Permanent mandibular canine with two roots and two root canals: Two case reports. Saudi Endod J 6(2): 98-100.

16. Heling I, Gottlieb-Dadon I (1995) Chandler N. Mandibular canine with two roots and three root canals. Dent Traumatol 11(6): 301-302.

17. Orguneser A, Kartal N (1998) Three canals and two foramina in a mandibular canine. J Endod 24(6): 444-445.
18. Sikri V, Kumar V (2003) Permanent human canines: Configuration and deviations of root canals: An in-vitro study. J Conserv Dent 6(4): 151152.

19. Kaffe I, Kaufman A, Littner MM, Lazarson A (1985) Radiographic study of the root canal system of mandibular anterior teeth. Int Endod J 18(4): 253-259.

20. Patel S (2009) New dimensions in endodontic imaging: Part 2. Cone beam computed tomography. Int Endod J 42(6): 463-475.

21. Carr GB (1992) Microscopes in endodontics. J Calif Dent Assoc 20(11): 55-61.

22. Arora A, Acharya SR, Sharma P (2015) Endodontic treatment of a mandibular first molar with 8 canals: A case report. Restor Dent Endod 40(1): 75-78.

23. Caliskan MK, Pehlivan Y, Sepetçioglu F, Türkün M, Tuncer SS (1995) Root canal morphology of human permanent teeth in a Turkish population. J Endod 21(4): 200-204.

24. Arora V, Nikhil V, Gupta J (2013) Mandibular canine with two root canals - An unusual case report. Int J Stomatol Res 2(1): 1-4.

25. Holtzman L (1997) Root canal treatment of a mandibular canine with three root canals. Case report. Int Endod J 30(4): 291-293.

26. Slowey RR (1974) Radiographic aids in the detection of extra root canals. Oral Surg Oral Med Oral Pathol 37(5): 762-772.

27. Fava LR, Dummer PM (1997) Periapical radiographic techniques during endodontic diagnosis and treatment. Int Endod J 30(4): 250261.

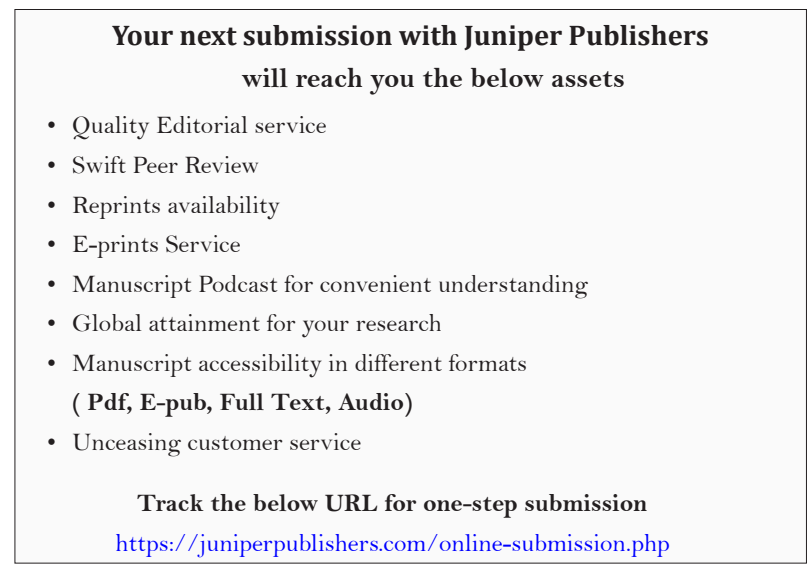

